\title{
In Search Of Customer Experience Management In Service Industry The Importance Of Experiential Interfaces
}

\author{
Kaveh Abhari ${ }^{1}$, Mahmod Sabri Haron ${ }^{2}$, and Norizan Mat Saad ${ }^{3}$ \\ \{kabhari@sdsu.edu'1,msabri@usm.my²,nsaad@yu.edu.sa ${ }^{3}$ \} \\ ${ }^{1}$ Fowler College of Business, San Diego State University, San Diego, USA \\ ${ }^{2}$ School of Management, Universiti Sains Malaysia, Penang, Malaysia \\ ${ }^{3}$ College of Business Administration, Al Yamamah University, Riyadh, Saudi Arabia
}

\begin{abstract}
Customer Experience Management (CEM) is a strategic and valuable marketing mechanism yet underexplored in the service industry. Marketing literature offers two common approaches to managing service experience: managing the experiential aspects of service and managing service touchpoints. Since both approaches come with some limitations, this study attempts to understand how service firms effectively manage customer experience in practice. This research built on empirical data from the review of five best practices. The findings revealed the key role of 'experiential interfaces' in the success of these cases. The study also identified the key practices supporting CEM at two levels of core offerings and supplementary services. The study provides an empirical foundation for the conceptualization and operationalization of experiential interfaces for future research.
\end{abstract}

Keywords: Customer Experience, Customer Experience Management, Service Industry, Case Study, Malaysia.

\section{Introduction}

Customer Experience Management or CEM is a topic that deserves further exploration. Marketing literature as yet falls shorts in offering a comprehensive and realistic picture of CEM -especially in the service industry- despite all the recent development (Caru \& Cova, 2015; Schmitt \& Zarantonello, 2013). One of the key questions in the service industry is 'how' firms can design, deliver, and enhance distinctive service experience. Although, many studies have addressed this question from a consumer behavior perspective (e.g. Kwortnik \& Thompson, 2009), reflection from the organizational angle is yet limited (Arkadan et al., 2017; Kandampully et al., 2018; Kranzbühler et al., 2017). Recent debates on CEM structure and implementation were also limited to conceptual studies. Marketing scholars thus call for fundamental research addressing managerial aspects of customer experience (e.g. Hwang \& Seo, 2016).

While some theoretical evidence suggested how firms could manage customer experience in an integrated fashion, there are limited empirical studies on the role of experiential values in service experience formation and their relationships with customer touchpoints. Moreover, there are only a few limited studies on the service experience design and management (Caru \& Cova, 2015; Jaakkola et al., 2015; McColl-Kennedy, Cheung \& Ferrier, 2015; Kwortnik \& Thompson, 2009). There are also limited studies on CEM organization and organizational requirements and capabilities (e.g. Ailawadi et al., 2009; 
Fatma, 2014). Therefore, further investigation of CEM antecedents may lead to more successful implementations of CEM in practice (Fatma, 2014).

This study is an initial attempt to understand CEM in the service industry as it is practiced in reality not theoretically defined in the literature. Using a case study, this research explains how customer experience can be managed in the service industry. In particular, the study identified the key success factors and the organizational requirements to help CEM achieve its desired outcomes.

\section{Background}

CEM in the service industry refers to designing and delivering memorable personal service experience (McColl-Kennedy et al., 2015). Kwortnik and Thompson (2009) believe this term comes from two joined disciplines: 'service management' in terms of process and 'customer management' in terms of experience marketing. Tseng et al. (1999) suggested three practices for managing service experience: mapping customer experience figures out the opportunities and improve service operations to create a better experience. Fynes and Lally (2004) described CEM as a service process development. CEM was also conceptualized as experience design, which is conceptualized as an approach to orchestrating tangible and intangible service elements (Pullman \& Gross, 2004). In another study, Pullman and Gross (2003) conceptualized CEM in managing service-context, engagement, and time. More recently, Ardakan et al. (2017) suggested strategizing, operating, and enabling as three main components of CEM and Kandampully et al. (2018) identified technology, design, operation, HR, strategy, marketing, and social media as the main enablers of CEM in the service industry.

These studies focused on the tactical aspects of CEM from an operational viewpoint without considering the phenomenological process of experience co-creation and the critical role of experiential values. Furthermore, these studies did not address the source of experiential values, the role of knowledge and personal involvement in service experience cocreation as suggested by Caru and Cova (2015) and McColl-Kennedy et al (2015).

Due to the lack of an accepted foundation, diverse definitions, and untested conceptualizations, the form and organization of CEM in practice is still unclear (Ardakan et al., 2017; Fatama, 2014; Homburg et al., 2017; Kandampully et al., 2018; Verhoef et al., 2009). On one hand, CEM has been defined as managing experiential values and on the other hand, as a mechanism to manage touchpoints.

\subsection{CEM as Managing Experiential Values}

Strategic experiential modules typically refer to brand experience (e.g. Brakus et al., 2009; Schmitt et., 2015). Brand experience reflects the static facets of experience formation, which engage customer under the brand name (Keller \& Lehmann 2006; Walden, 2017) and it is articulated as feelings, sensation, and behavioral, social and intellectual response to brandrelated stimuli (Brakus et al., 2009). Brand experience is thus associated with both corporate and product level experience in the service context (Voorhees et al., 2017). Keller and Lehmann (2006) argued that brands reflect the complete experience that customers have with products. Similarly, Schmitt (2003) depicted brand experience as a combination of the offering (experiential features), manifestation, and experiential communication. Morrison and Crane (2007) defined brand experience based on emotional branding and argued that only branded experience can be memorable and consequently engages customer emotionally and creates an emotional bond with unique trust and satisfaction. This association is the 
cornerstone of the memorability of experience. Moreover, emotional attachment is a result of the engaging customer with the branded experience with high level of involvement (Brakus et al., 2009; Crosby \&Johnson, 2005; Fatma, 2014; Morrison \& Crane, 2007).

This approach to CEM encourages service firms to identify experiential values of their service offerings or design supplementary services with experiential values. The emphasis here is on the nature of service offering -its traits- rather than the process of experience formation.

\subsection{CEM as Managing Touchpoints}

On the other end of the spectrum, we have CEM as a practice of customer interface (or touchpoint) management. This approach mainly focuses on the process - service delivery- but not the service essence. This group of schoolers believes that experience is dependent on the acquisition of offerings from a cluster of interactions at the service touchpoints (Tsai, 2005; Verhoef et al., 2009). To support this approach, they claimed that customer experience is shaped mostly by interactions which are delivered through the service touchpoints (Chattopadhyay \& Laborie, 2005). From this perspective, managing customer interface, therefore, refers to the management of reciprocal exchange between customers and the service firm. CEM is also responsible for communicating the experiential values through meaningful touchpoints to enhance the brand image rather than design those values. That means the interface is a vehicle for brand experience, not the brand experience.

\subsection{Experiential Interfaces}

We believe CEM should deal with both experiential values associated with the service essence and the interactional values related to the service delivery. The key part of this combination is experiential interfaces. A proper interface setting provides a chance to serve customers with rational (trust, speed), sensorial (visual identity), pragmatic (co-creating), and emotional values (fun, challenge).

In service context, the importance of interaction stems from the essence of service, since, service experience usually goes along with the service creation and consumption at the same place and in the same time (Lau et al., 2005). The importance of interface in shaping service experience is more notable since customer decision is strongly influenced by that during that exchange of experiential values. These moments-of-truth shapes customers experience and consequently forms their perception of service essence (Caru \& Cova, 2015). By managing experiential interfaces, service firms offer customers more opportunities to co-create desirable experience through branded stimuli. Hence, service firms may lose the control over the service essence if they fail to properly manage experiential interfaces. To show the importance of experiential interfaces in formulating CEM, we designed a case study to review the best practices that have successfully implemented CEM for a long time.

\section{Method}

Reviewing best practices can provide evidence for the earlier maturity of any research model (Yin, 1994). Considering the limitations in the CEM literature, reviewing best practices also offers a better understanding of the possible framing (Ghauri, 2004; Scholz \& Tietje, 2002). Therefore, a case study was designed to find explanations and features that are common within the best practices. This method also helps with identifying the important 
organizational antecedents that were overlooked by the researchers or practitioners in the service industry.

The nature of service experience is not so different across the service sectors (Otto \& Ritchie, 1996). Therefore, the cases were selected from different service industries to develop a more inclusive understanding of CEM and its success factors. Eleven cases were initially nominated from Top Five service brands in each service category based on Fortune 500 and Fortune Global 500. Subsequently, three organizations were chosen from the list according to the availability of supporting evidence in the literature as well as their presence in the Malaysia market. This consideration later allowed us to adopt the results of westernexperiences in the local context. Regarding the local brands, two local brands were chosen from the five nominees in the list of Malaysia Most Valuable Brands, which published by Interbrand. The final list of cases included Westin, Starbucks, Singapore Airline, CIMB, and Maxis.

We used published case studies in books, academic journals and managerial reviews, which refers to these cases as CEM best practices. We also used the published materials by the firms, which explicitly or implicitly discussed the events, processes, and outcomes of CEM. The observations of the firms' marketing practices such as differentiation strategy, promotion, and online presences were the third source of evidence. The customers' reviews and other anecdotal evidence were also cited to support the discussion.

Pattern matching was the main analysis technique we used (Bryman \& Bell, 2007). The analysis started by coding the materials as the core and ancillary practices and categorizing evidence to gain further insights into the CEM practice in the service industry. Within case and cross-case comparison helped to reveal the pattern (Eisenhardt, 1989; Yin, 1994). The comparison allowed to identify the core categories and key relationships between them. Through cross-case comparison, we looked for theoretical replication for a stronger conclusion (Yin, 1994). A quasi-quantification method was also employed in this study to facilitate the comparison (Bryman and Bell, 2007).

\section{Case Report}

The following section briefly reports on the results and discusses the CEM practices and achievements in these best-practices.

\subsection{Westin: 'Experience the Heaven on Earth'}

Westin Hotel chain is a well-known example of offering positive and memorable customer experience. Westin exemplifies the service clue integration toward customer experience. Sue Brush, former senior vice president put the hotel story in this way: “...we've maintained our commitment to quality, people, consistency, and innovation. Today we' re obsessed with creating unforgettable guest experiences and infusing a spirit of renewal into every aspect of the Westin experience." Upgrading the service experience at the key touchpoints by was the main reason behind the Westin's success. Westin offers memorable experience by blending the core service with experiential values. At Westin, all senses work together to let guests co-create own experiences. Comfort, style, revitalizing, and multisensory appeal are the experiential values employed by Westin at every touchpoint. Westin was also the first hotel that personalizes offerings using a CRM system. Starwood claimed, "It [Westin] has made history with a succession of momentous 'firsts' throughout the years". Westin started by differentiating core service experience (e.g. Heavenly offerings by launching Heavenly Bed, Heavenly Bathroom, Heavenly Crib, Westin Workout). Then, it 
enhanced and differentiated the core offerings with supplementary services (e.g. Sensory Welcome) and think experience (i.e. Superfoods RX) to act experience (e.g. Run WESTIN) and social experience (Unwind ${ }^{\mathrm{s} m}$-a Westin evening ritual).

\subsection{Starbucks: 'It's Bigger than Coffee'}

Starbucks is the fifth world's most admired companies and the second world valuable food brand with the worth of $\$ 44$ billion in 2018 . Starbucks has turned the consumption of a routine commodity to a branded experience. Wyner (2003, p. 6) argued that "The Starbucks experience is certainly more than coffee; it combines the location, the ambiance, the types of people that might be there, and the activities they might engage in". Today, Starbucks experience is also extending beyond the coffee and coffeehouse. The result of such practice is customer loyalty- more than 18 purchases a month per customer. Starbucks has changed the focus form service quality to service experience in 2008. Along with this decision, Starbucks set up In-Store Experience department besides its marketing department.

Starbucks remarkable efforts to manage customer experience can be categorized into three main domains: store experience, brand experience and employees. Starbucks focuses on offering experiential values, while sticking to the original theme, Starbucks enhance in-store experience details through experiential values, employees, and facilities (a) sense experiences (e.g. music, smell, interior design, taste and flavor, cleanliness); (b) think experience (e.g. location, coffee varieties, nutrition facts); (c) feel experience (e.g. a pleasant and relaxed environment, attentive interaction); (d) relate experience (e.g. alternative lifestyle, communities exchange, guest artists); and (e) act experience (e.g. entertainment, online activities, music download).

Additionally, Starbucks brings brand value across all touchpoints and then, tests various touchpoints to inspire different customers with different tastes. Cyberspace plays a vital role in this movement. For example, they had more than four platforms to engage customers in challenging and innovative experience, (My Starbucks Idea, Shared planted, Starbucks V2V, and (Starbucks) ${ }^{\mathrm{Red}}$ ). In this way, Starbucks tries to engage its customers in meaningful philanthropy and innovation efforts.

Starbucks manages employee experience, based on 'love what you do' concept. Respect, appreciation, and equality are the main traits of employee experience at Starbucks. They invest highly in training, empowering, supporting, and engaging employees to prove 'Starbucks is like no place they have ever worked'. The result of this approach makes the Starbucks 24th in '100 Best Companies to work for' by Fortune as well as top rank in '100 Best Corporate Citizens' and 'Word's Most Ethical Companies'.

\subsection{Singapore Airlines: 'Rediscover the romance of flying'}

For a long period of time, Singapore Airlines (SIA) is considered as one of admired service firms. SIA, one of the five-star airlines, delivers excellent experiences in all touchpoints including waiting experience at Airport and offers new innovative services before its competitions. SIA enhances overall service experience with reliability, quietness, roominess, trust, and safety. Edvardsson (2005) believed that SIA's achievements do not only rely on these service qualities but on creating favorable experiences. Paying attention to details of experience is the root of SIA success. Innovation, reviewing processes, understanding customer's needs, and managing employees' experience are the central capabilities. 
SIA always keeps brand promises with positive service experience and experiential positioning. They turn in-flight service into a memorable experience using themes based on Asian tradition and hospitality. Their annual campaigns have specific themes reflecting on customers' experiential needs.

SIA's differentiation strategies are based on their innovation in experience creation. Innovation begins with creative in-flight experience co-creation; thus, customers usually have a memorable experience because of the originality in co-created experience. SIA's product innovation manager believes that innovation does not necessarily mean new ideas when firms can offer something better than the mundane standard, it can be considered as an innovation. Given the company history, the current typical services were SIA's innovative offerings in the early 1970s (e.g. in-flight entertainment experience). Third,

Employees are at the heart of SIA customer experience. Careful recruitment, meticulous training, and continuous reinforcement become the principles in SIA. SIA values employees and empowers them as the key interface to deliver a superior experience. Employees have a positive experience with the brand themselves as SIA provides a positive work environment and various types of supports. SIA as compared to its competitors has a very rigorous system for staff recruitment and training. SIA sets up an annual camp, brings all executives to identify opportunities and encourage them to innovate. This type of programs and effective incentive system are used to boost the employees' participation in customer experience management efforts. Lastly, to provide superior experiences, SIA has invested in the development of a new Customer Experience insight system supporting employees across different touchpoints to quickly identify their customers' needs in order to create opportunities to deliver the right service with greater efficiency.

\subsection{CIMB: 'New Banking Experience'}

CIMB is fifth Malaysia's most valuable brand - I \$1,716 million, 2016. CIMB is ranked as 'Best Private Bank in Malaysia' by 'Finance Asia's Country Awards', 'Bank of the Year' for Malaysia by 'The Banker', 'Best Islamic Bank' in Asia by 'Euro Money Islamic Finance Awards'. CIMB is one of the best examples in Malaysia that manage customer experience effectively. In CIMB, delivering quality customer experience is regarded as a fundamental business practice. CIMB has enriched brand value with superior customer experience since 2012. Head of Consumer Sales and Distribution, Sulaiman Mohd Tahir, stated that "We wanted to create a business floor that fuses various banking components into a seamless banking experience for our customers".

CIMB has started CEM by enhancing service delivery in branches for example by innovative branch design. This attempt leads to winning an award for 'Excellence in Branch Innovation' among the Asian bankers. CIMB also establishes new interfaces to enhance the experience and let customers take some shortcuts in some banking services. To engage customers in experiential events and create memorable experiences, CIMB redesigns its reward program. For example, CIMB offered travel passes to international events (e.g. Formula 1 Tour) through its campaigns. Moreover, act experience promotes CIMB saving packages. CIMB set up EcoSave Savings Account as the first Malaysian environment-related savings account that enables customers to contribute to the environmental causes. ' $C I M B$ Cares' empowers social experience via consumer banking. CIMB Cares brings all NGOs together in a community and let customer donate to the favorite NGO. CIMB also empowers customers to co-create social experience and propose initiatives relevant to their own communities for example by sponsoring events, supporting social causes, performing arts, and hosting of educational camps. 
CIMB focuses on its customer lifestyle to promote the customized packages (e.g. kids' plan, retirement plan). For example, Easy Life was a plan to engage women in customized experiences of saving while offering a unique lifestyle. CIMB has the leading role in educational experience; for instance, they are recognized as the most innovative award for investor education in the region. CIMB Wealth Advisors was also launched to offer new educational experience. Given escapist experience, CIMB offers online gaming such as 'Secret Online', 'Online Game Reload', and 'Self-developed Game'. To enriches experience co-creation, CIMB promotes fun along with its internet banking and mobile banking (e.g. Dream Deposited Drive and Hunting Octo challenge customer to win cash prize through online banking).

\subsection{Maxis: My Life, My Maxis}

Maxis is the tenth valuable brand in Malaysia at \$1,080 million in 2016. Maxis was recognized as Service Provider of the Year by Frost \& Sullivan and as Mobile Operator of the Year by Asian Mobile News Award. Although Maxis is a young brand, it is the leading mobile communication providers in Malaysia with more than 11 million customers. Maxis is recognized by Asian Wall Street Journal as 'Most Admired Company' and 'Best Asian Mobile Operator' by Asian Mobile News.

Maxis' growth is based on three key approaches: bringing innovation, excellent customer experience, and value to stakeholders. Maxis' former Chairman noted, "Our sustained future investments should enable us to enhance customer experience and give us a strong platform for continued growth". Customer experience is the hearts of Maxis' marketing strategies. Excellent customer experience and innovation across all touchpoints are vital to convey brand promises for Maxis. Maxis like many other market leaders turned to experience marketing; they sponsor concert and sport events and admin many musical events to engage customers in a memorable event. Maxis improves value co-creation by various means such as personal relationship (e.g. dating), entertainment (e.g. event, nightlife and shopping update), social (e.g. traffic updates), food (i.e. restaurant finder), and travel (e.g. hotel finder).

In contrast to its competitors, Maxis has a clear and comparable approach to managing customers' emotions in advertisements and its campaigns through lifestyle marketing. Maxis also personalize experience in co-creating manner, for example by offering Zon Islamic, Ekspresiku, Unifun, MBlog, Indian Portal, and Her Maxis. Maxis alters cellophane experience with Fun \& Innovation Series (e.g. new mobile gaming experience). Relationship Tips \& News is an innovative service that goes beyond typical mobile services. Lastly, offering social experience through launching clubs (e.g. FrenClub, Youth Club) was used to enrich and cocreated experience. Her Say was one of Maxis 'Reach Out' efforts allowing customers to share, their view on love, beauty, relationship or career.

\section{Case Analysis}

Pattern-matching was used for data analysis (Yin, 1994). First, the key components were identified and coded for each case. For each case, the core components of their CEM strategy, as well as the key supporting practices, are identified. The coding process continued by labeling the core and ancillary factors. Subsequently, the relationships between the coded items were determined by inspecting the replications. Quasi-quantification was then utilized to model the level of resemblance between the cases (Bryman and Bell, 2007). However, we observed the common focus was on the experience co-creation at touchpoints. 
It was remarkable how these brands design and maintain their value propositions to delight customers by investing in experiential interfaces. The case study supported that orchestrating customer experience is the key differentiation strategies for service firms. The results confirmed that experience formation has a close relationship with phenomenological value co-creation. It also revealed that managing experiential aspects of value co-creation can be a right foundation to CEM. The common theme among the cases was designing and managing the experiential interfaces either related to the core services or supplementary offerings. The observed practices have a shared characteristic by which service encounter can be co-created with a high level of customer involvement or experiential consumption. The findings revealed that offering experiential values such as emotional experience, act experience, cognitive experience, social experience, and lifestyle is the core component of CEM strategy at these organizations. These values can generate positive experience to engage the customer, create specific feelings, alter value perception, and control decision-making. The case analysis also highlighted the important organizational functions and their relationships that enables CEM. We identified customer intelligence, innovation, and technology applications as the key antecedents. Among these enabling factors, the main source of superior experience was innovation -for both core and supplementary offerings.

\section{Conclusion}

This study suggests CEM is more than monitoring customer interactions but managing experience co-creation opportunities. This process can be designed to engage customers through both core service offerings and supplementary offerings but at the key customer touchpoints. This study also suggests that values are phenomenologically co-created by customers and not solely by the service firms. Therefore, to manage customer experience, organizations should design and manage the experiential stimuli supporting experience cocreation process. To achieve this goal, service firms need to invest in the key supporting or enabling functions such as customer analytics, innovation, and technology applications. Above that, to enhance the quality of experience, firms should invest in frontline employees' experience as the main interface. These efforts follow theoretical evidence that signifies the priority of internal customer in the context of CEM.

Furthermore, CEM highly depends on customer touchpoints that purposefully designed for experience co-creation. Therefore, it is reasonable to design or choose a right collection of interfaces for CEM implementation rather than going after all the customers' interaction. Enriching customer interface with experiential values and offering interaction personalization are critical to enhancing customer experience and strengthening the emotional bond. Failure in managing interface leads to serious problems in customer retention.

\section{References}

[1] Ailawadi, K. L., Beauchampb, J. P., Donthu, N., Gauri, D. K., \& Shankar, V. 2009. Communication and Promotion Decisions in Retailing: A Review and Directions for Future Research. Journal of Retailing, 85 (1), $42-55$.

[2] Arkadan, F., Macdonald, E. K., \& Wilson, H. N. 2017. A Systematic Literature Review of Practices in Customer Experience Management. In Marketing at the Confluence between Entertainment and Analytics, Developments in Marketing Science: Proceedings of the Academy of Marketing Science.

[3] Brakus, J. J., Schmitt, B. H., \& Zarantonello, L. 2009. Brand Experience: What Is It? How Is It Measured? Does It Affect Loyalty? Journal of Marketing, 73 (3), 52-68. 
[4] Bryman, A., \& Bell, E. 2007. Business Research Method (2nd ed.). New York, NY: Oxford University Press.

[5] Carù, A., \& Cova, B. 2015. Co-creating the collective service experience. Journal of Service Management, 26(2), 276-294.

[6] Chattopadhyay, A., \& Laborie, J. 2005. Managing Brand Experience. Journal of Advertisement Research, 45 (1), 9-16.

[7] Crosby, L. A., \& Johnson, S. L. 2005. Managing Experiences. Marketing Management, 14 (1), 11-12.

[8] Edvardsson, B. 2005. Service quality: beyond cognitive assessment. Managing Service Quality, 15 (2), 127-131.

[9] Eisenhardt, K. M. (1989. Building Theories from Case Study Research. The Academy of Management Review, 14 (4), 532-550.

[10] Fatma, S. 2014. Antecedents and Consequences of Customer Experience ManagementA Literature Review and Research Agenda. International Journal of Business and Commerce, 3(6), 32-49

[11] Fynes, B., \& Lally, A. M. 2008. Innovation in Services: From Service Concepts to Service Experiences. In B. Hefley, \& W. Murphy, Service Science: Research and Innovations in the Service Economy (pp. 329-333). US: Springer.

[12] Ghauri, P. 2004. Designing and Conducting Case Studies in International Business Research. In R. Marschan-Piekkari, \& C. Welch, Handbook of qualitative research methods for international business (pp. 109-124). Northampton, MA: Edward Elgar.

[13] Homburg, C., Jozić, D., \& Kuehnl, C. 2017. Customer experience management: toward implementing an evolving marketing concept. Journal of the Academy of Marketing Science, 45(3), 377-401.

[14] Hwang, J., \& Seo, S. 2016. A critical review of research on customer experience management: Theoretical, methodological and cultural perspectives. International Journal of Contemporary Hospitality Management, 28(10), 2218-2246.

[15] Jaakkola, E., Helkkula, A., \& Aarikka-Stenroos, L. 2015. Service experience cocreation: conceptualization, implications, and future research directions. Journal of Service Management, 26(2), 182-205.

[16] Jain, R., Aagja, J., \& Bagdare, S. 2017. Customer experience - a review and research agenda. Journal of Service Theory and Practice, 27(3), 642-662.

[17] Kandampully, J. 2000. The impact of demand fluctuation on the quality of service: a tourism industry example. Managing Service Quality, 10 (1), 10-18.

[18] Kandampully, J., Zhang, T., \& Jaakkola, E. 2018. Customer experience management in hospitality: A literature synthesis, new understanding, and research agenda. International Journal of Contemporary Hospitality Management, 30(1), 21-56.

[19] Keller, K. L., \& Lehmann, D. R. 2006. Brands and Branding: Research Findings and Future Priorities. Journal of Marketing Science, 25 (6), 740-759.

[20] Kranzbühler, A.-M., Kleijnen, M. H. P., Morgan, R. E., \& Teerling, M. 2017. The Multilevel Nature of Customer Experience Research: An Integrative Review and Research Agenda. International Journal of Management Reviews, 20(2), 433-456.

[21] Kwortnik, R. J., \& Thompson, G. M. 2009. Unifying Service Marketing and Operations with Service Experience Management. Journal of Service Research, 11 (4), 389-406.

[22] Lau, P. M., Akbar, A. K., \& Fie, D. Y. 2005. Service Quality: A Study of the Luxury Hotels in Malaysia. The Journal of American Academy of Business, 7 (2), 46-55. 
[23] McColl-Kennedy, J. R., Cheung, L., \& Ferrier, E. 2015. Co-creating service experience practices. Journal of Service Management, 26(2), 249-275.

[24] Morrison, S., \& Crane, F. G. 2007. Building the service brand by creating and managing an emotional brand experience. Journal of Brand Management, 14 (5), 410421.

[25] Otto, J. E., \& Ritchie, J. R. (1996. The Service Experience in Tourism. Tourism Management, 17 (3), 165174.

[26] Pullman, M. E., \& Gross, M. A. 2003. Welcome to Your Customer Experience: Where You Can Check Out Any Time You'd Like, But You Can Never Leave. The Journal of Business and Management, 9 (3), 215-232.

[27] Pullman, M. E., \& Gross, M. A. 2004. Ability of Experience Design Elements to Elicit Emotions and Loyalty Behaviors. Decision Sciences, 35 (3), 551-577

[28] Schmitt, B. 2003. Customer Experience Management. New Jersy: John Wiley \& Sons Inc.

[29] Schmitt, B., \& Zarantonello, L. 2013. Consumer Experience and Experiential Marketing: A Critical Review. Review of Marketing Research. 10, $25-61$.

[30] Schmitt, B., Joško Brakus, J., \& Zarantonello, L. 2015. From experiential psychology to consumer experience. Journal of Consumer Psychology, 25(1), 166-171.

[31] Scholz, R. W., \& Tietje, O. 2002. Embedded Case Study Methods. Integrating Quantitative and Qualitative Knowledge. Thousand Oaks: Sage.

[32] Tseng, M. M., Qinhai, M., \& Su, C.-J. (1999. Mapping Customers' Service Experience for Operations Improvement. Business Process Management Journal, 5 (1), 50-64.

[33] Tsai, S. P. 2005. Integrated marketing as management of holistic consumer experience. Business Horizons, 48 (5), 431-441.

[34] Verhoef, P. C., Lemon, K. N., Parasuraman, A., Roggeveen, A., Tsiros, M., \& Schlesinger, L. A. 2009. Customer Experience Creation: Determinants, Dynamics and Management Strategies. Journal of Retailing, 85 (1), 31-41.

[35] Wyner, G. A. 2003. How Do You Measure the Customer Experience? Marketing Research, 15 (1), 6-7.

[36] Yin, R. K. (1994. Case Study Research, Design and Methods. In R. K. Yin, Applied social research method series (3rd ed., Vol. 5). Thousand Oaks, CA: Sage Publications. 